\title{
Interannual variability characteristics of the eastern Minnesota (USA) temperature record: implications for climate change studies
}

\author{
Richard H. Skaggs ${ }^{1 *}$, Donald G. Baker ${ }^{2}$, David L. Ruschy ${ }^{2}$ \\ ${ }^{1}$ Department of Geography, University of Minnesota, 414 Social Sciences Bulding, 276 - 19th Ave South, Minneapolis, \\ Minnesota 55455, USA \\ ${ }^{2}$ Department of Soil Science, 1991 Upper Buford Circle, University of Minnesota, St. Paul, Minnesota 55108, USA
}

\begin{abstract}
Running standard deviations of the eastern Minnesota (USA) mean annual temperatures were calculated for a variety of averaging periods. We used the 13 yr running standard deviation to illustrate the general decline to minima near the end of the record. These minima were outside of the 2 -tailed $1 \%$ bootstrapped confidence interval. The most recent running standard deviations showed an increase. These results compare well with the limited number of other studies and data available and demonstrate the potential difficulty associated with using the recent past to estimate the natural variability of climate.
\end{abstract}

KEY WORDS: Temperature variability $\cdot$ Climate change $\cdot$ Standard deviations

\section{INTRODUCTION}

In an earlier study, we (Baker et al. 1993) called attention to a period of 'benign climate' with low levels of interannual variability in agricultural production and climate variability. This study investigates the degree to which interannual variability of climate varies over time, i.e. time variations in the 'natural variability' of climate. The recognition of 'significant' climate fluctuations or changes depends to a considerable degree on the magnitude of this natural variability. It is clear that a determination of the variability and its fluctuations over time requires a record or records of high quality and of long duration.

There are few analyses of temperature variability over the long term largely because of the dearth of high quality long-term records. We believe that the eastern Minnesota (USA) record is sufficiently homogeneous and of sufficient duration, currently 173 yr, that it can provide a unique view of the time history of temperature variability in the heart of the North American continent. It is essentially a homogenized combi-

•E-mail:skaggs@atlas.socsci.umn.edu nation of 2 stations, Fort Snelling and Farmington $3 N W$. The history, location, and uniqueness of this temperature record have been reported (Baker et al. 1985) with the unadjusted record applied in 2 early studies (Baker 1960,1962) and the adjusted record in more recent studies (Skaggs \& Baker 1985, 1986 , 1989). It is the longest record west of the Mississippi River and is exceeded in length in North America only by a very few East Coast U.S. stations, many of which are confounded by urban growth and industrialization.

The 2-phase regression line of the eastern Minnesota temperature record trend obtained by Skaggs \& Baker (1989) has been brought up to 1992 (Fig. 1). The current warming trend began in about 1867 . The slope of this temperature trend is $0.013^{\circ} \mathrm{C}$ per year, which compares with $0.0045^{\circ} \mathrm{C}$ per year for the $1861-1989$ period of the Northern Hemisphere time series (IPCC 1990). Visual inspection of the time series gives the impression that the interannual variation in mean annual temperature has changed over time. In particular it appears that the interannual variability was higher in the last century. There also seems to be a minimum in interannual variability 3 or 4 decades ago. In the most recent 2 decades, the trend seems to be toward increased interannual variability. 


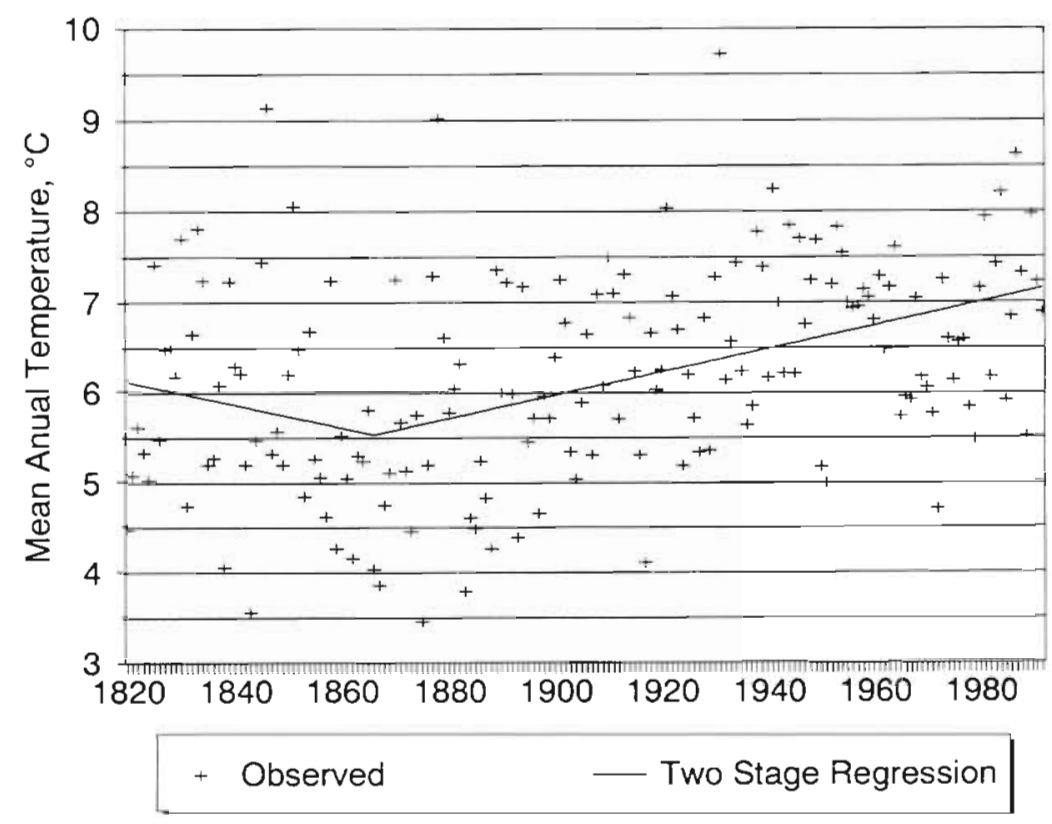

Fig. 1. Mean annual temperatures of the eastern Minnesota (USA) record. A 2-phase linear regression trend is shown data. One thousand random samples (drawn with replacement) of 13 mean annual temperatures were selected from the detrended time series and the standard deviation calculated for each. We use the empirical frequency distribution of the bootstrapped standard deviations as a means of assessing the probability of occurrence of running standard deviations calculated from the eastern Minnesota record, e.g. the largest and smallest 50 values combined to represent the 1\%, 2-tailed limits.

The 13 yr running standard deviation of the eastern Minnesota record has varied a great deal over the past $150 \mathrm{yr}$ (Fig. 2 with the data plotted at the endpoint of the 13 year period). In the last century the 13 yr running standard deviation was a factor of 3 higher than in recent times. From near the beginning of the present century, the $13 \mathrm{yr}$ running standard deviation decreased more or less regularly to a sharp mini-

\section{ANALYSIS AND RESULTS}

The measure of interannual variability we use is the running standard deviation. Running standard deviations of various lengths (e.g. 10, 13, 20,30, 50, and 75 yr) were calculated. In this paper we emphasize the 13 yr running standard deviation because it represents the length at which the minimum running standard deviation, the so-called 'benign climate,' occurred in the eastern Minnesota record (Baker et al. 1993). Two major problems immediately arise. First, the time series has significant serial correlation, with a lag-one autocorrelation of about 0.2 . Second, running standard deviations, constructed by adding and dropping one year at a time, are not based on independent samples. To account for the serial correlation, the 2-stage regression trend was removed prior to calculating the running standard deviations. The serial correlation was not significantly different from zero in the detrended time series.

The lack of independence makes assessment of the probability of a particular observed 13 yr running standard deviation difficult to calculate directly. Therefore, we used bootstrapping (Efron 1982) on the detrended

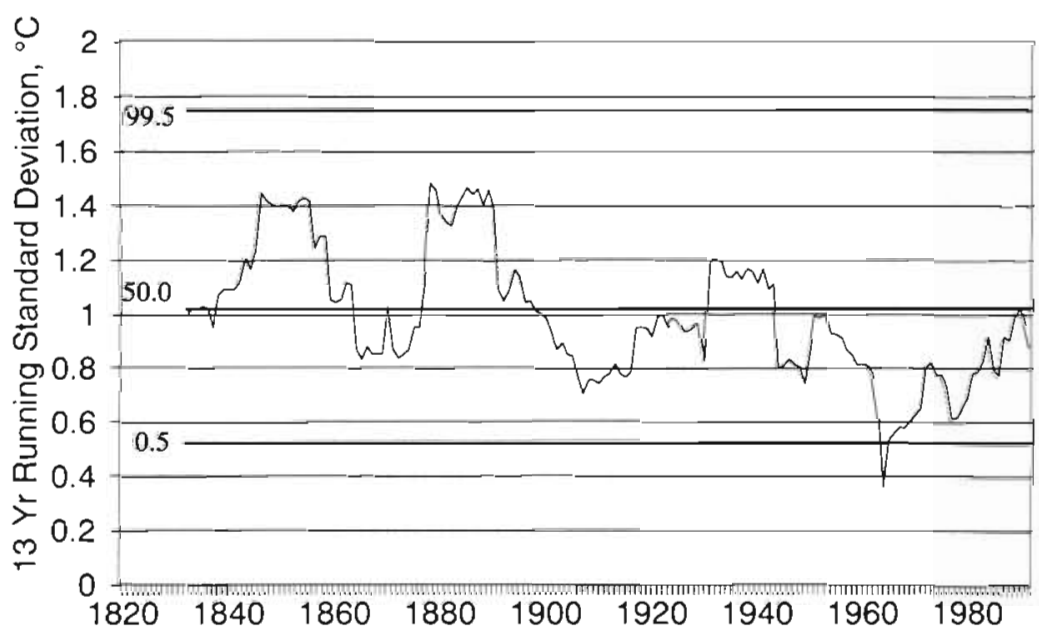

Fig. 2. The 13 yr running standard deviations of the eastern Minnesota mean annual temperatures, $1820-1992$. The 2 -tailed $1 \%$ bootstrapped confidence interval is shown. Data plotted at the end year mum in the middle to late 1960s. This minimum is in the smallest $0.5 \%$ of the frequency distribution of the bootstrapped values. Since then, the standard deviation has increased, although it remains much smaller than earlier in the record

A major question, of course, is whether the recent minimum in interannual variability is idiosyncratic to the eastern Minnesota record. We selected 33 stations with relatively long records distributed across the United States from the Historical Climatological Net- 
work (Quinlan et al. 1987). Serial correlations were calculated, and 1- or 2-stage detrending performed if necessary (Table 1) prior to calculating 13 yr running standard deviations. It is apparent (Table 1) that most of these stations have a minimum 13 yr running standard deviation at about the same time as the eastern Minnesota record. Indeed, nearly half of the stations experienced a minimum in the early 1970 s (Table 2). Fully two-thirds of the stations had the minimum in the decade of the 1970s. Thus the period of low interannual variablity appears to occur more or less simultaneously over the United States and is not a feature of the eastern Minnesota record only.

As another assessment of the consistency of the recent minimum in interannual variability, we performed a cluster analysis of the time series of 13 yr running standard deviations of the eastern Minnesota and the other 33 stations using the Wards minimum variance method (Ward 1963). Two groups, the western United States and the eastern United States, emerged with the dividing line running approximately from central Michigan to central Texas. The average 13 yr running standard deviations were calculated for each year (Fig. 3). A distinct minimum in the running standard deviation is evident in the average for each of the 2 groups

Boehm (1993) presents results with which we can compare ours directly. Variances of 'overlapping subintervals of 20 years' for 5 long-term Austrian temperature records divide into essentially 2 periods at all stations. Relatively high variability existed from the beginning of the records (one station record began as early as 1775) and lasted into the 1870 s when a change to markedly lower variability occurred that continued nearly to the end of the record. Coinciding with the variability change in the 1870 s was an instrument mounting and housing change at 4 of the stations. Since the fifth station, where instrumentation remained unchanged, exhibited a similar variability, Boehm (1993) attached no significance to the mounting and housing change. The eastern Minnesota record of 13 yr running standard deviations (Fig. 2) does show a brief variability decrease in the 1870 s, with a return to high variability until 1900. The post-1900 period in the eastern Minnesota record is one of relatively low variability. However, it does not exhibit the degree of uniformity found in the 5 Austrian stations, a feature to be expected due to the greater continentality of the Minnesota climate. Both the eastern Minnesota (Fig. 2) and the Austrian stations (Boehm 1993) exhibit an increase in variation that is centered around $1920-1940$ as well as a suggestion of an increase in variance at the end of the record.

Table 2. Frequency by end year of minimum 13 yr standard deviations, eastern Minnesota

\begin{tabular}{|cccc|}
\hline Year & Frequency & Year & Frequency \\
\hline 1855 & 1 & 1967 & 1 \\
1870 & 1 & 1970 & 1 \\
1899 & 1 & 1971 & 5 \\
1908 & 1 & 1972 & 10 \\
1956 & 1 & 1976 & 3 \\
1957 & 1 & 1977 & 1 \\
1962 & 1 & 1978 & 1 \\
1964 & 2 & 1979 & 1 \\
1966 & 1 & & \\
\hline
\end{tabular}




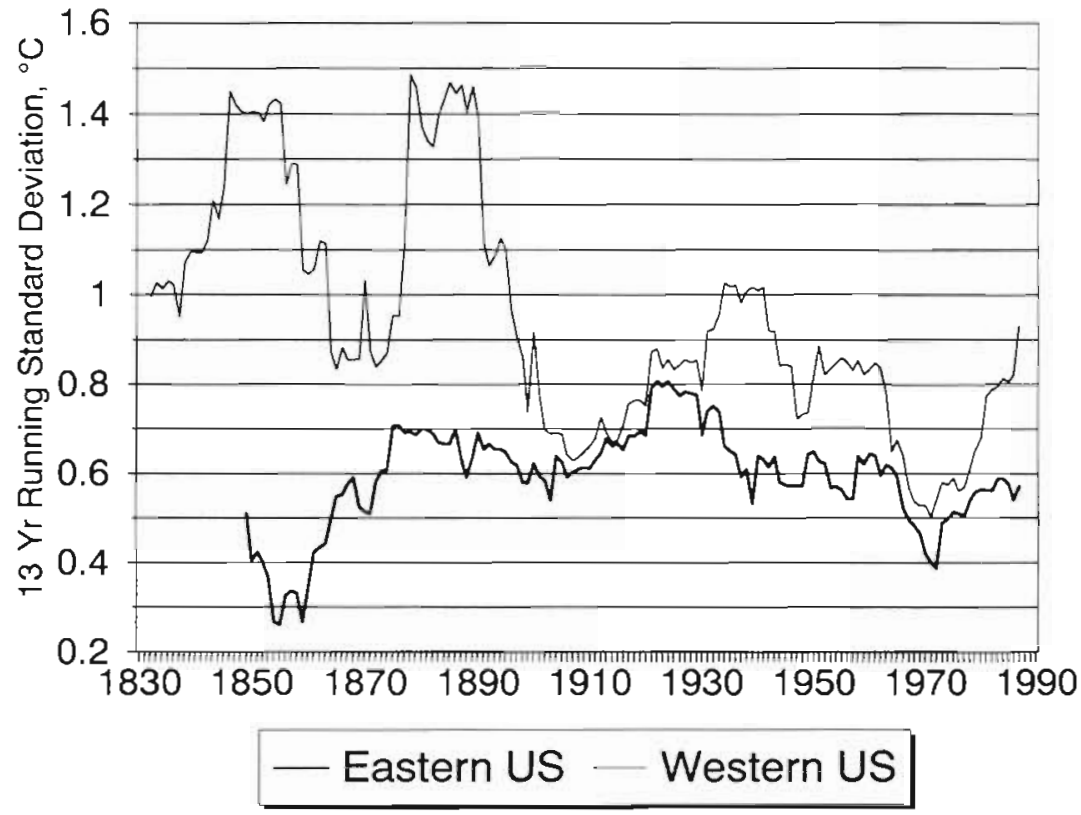

Fig. 3. Average 13 yr running standard deviations for the eastern and western United States. Each average contains 17 stations

record and close to the 2 -tailed $1 \%$ confidence limit derived from bootstrapping. In addition, the ratio of the largest to smallest 30 yr running standard deviation in the eastern Minnesota record is approximately 1.8 . The implication is that the low variability of the recent years could result in a serious underestimation of the natural variability.

\section{CONCLUSION}

The recent interannual minimum temperature variability that ended in the decade of the 1970 s was found to be a nearly consistent feature over the United States. Also the eastern Minnesota and 5 Austrian long-term temperature records show similarities in terms of high variability in the pre1870 period of record and the $1920-1940$ period, and the suggestion

Another comparison that can be made is with other North American high latitude stations with relatively long records. Toronto (Canada) and Sitka (Alaska, USA) were chosen for this purpose. Thirteen year running standard deviations were calculated for the full records of both stations. The $13 \mathrm{yr}$ running standard deviations for the period 1800-1980 were plotted long with the values for the eastern Minnesota record (Fig. 4). There is reasonable correspondence between the time series of running standard deviations, although it is far from perfect. The maxima of running standard deviations during the late part of the last century and the recent minimum are in agreement.

The issue of detection of a climate fluctuation or climate change, associated with anthropogenic warming, for example, is important and clearly related to the variability of climate. Hansen et al. (1988) and Hansen \& Lebedeff (1988) explored the possibility of detecting a temperature change signal using the standard deviation during the 1951-1980 'normal' period. In the case of the eastern Minnesota record, the 1951-1980 standard deviation is $0.78^{\circ} \mathrm{C}$, which is only slightly greater than the minimum 30 yr running standard deviation in the entire

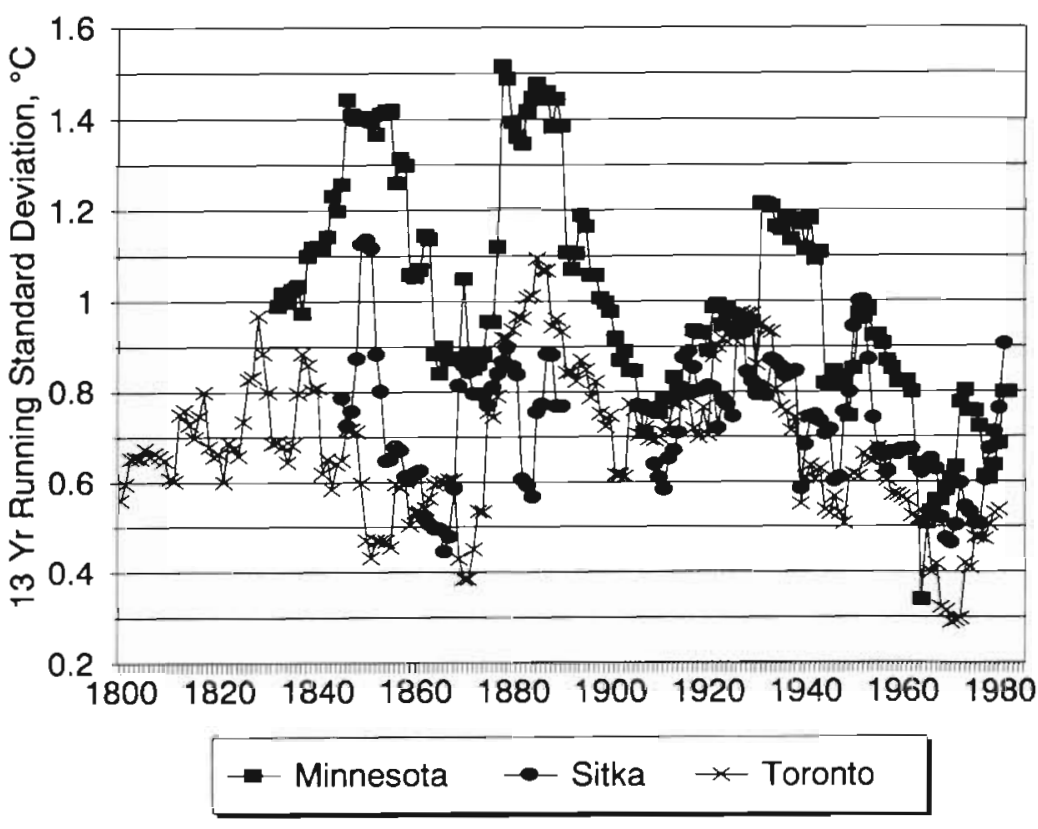

Fig. 4. 13 yr running standard deviations for eastern Minnesota, Toronto, and

Sitka. Data plotted at the end year of increased variance at the end of the records. Similarities between the eastern Minnesota and the Toronto and Sitka (Alaska) interannual temperature variabilities were also found.

In terms of climate change, the conclusion of this brief study is simple and obvious. The variability of temperature does not appear to be constant in time. As 
a result it is difficult to know which standard deviation to use in attempts to detect statistically significant climate fluctuations whether 'natural' or humaninduced. Certainly there is a substantial risk of underestimating the natural variability of climate if the last 3 to 5 decades are used as the standard unless a real inverse relationship between mean temperature and the standard deviation exists. The available evidence (van Loon \& Williams 1978, Diaz \& Quayle 1980, Brinkmann 1983) does not support any consistent inverse relationship between mean temperature and standard deviation. Indeed, the linear correlation between the running 13 yr mean annual temperatures and running 13 yr standard deviations for the eastern Minnesota data series is +0.2 .

\section{LITERATURE CITED}

Baker DG (1960) Temperature trends in Minnesota. Bull Am Meteor Soc 41:18-27

Baker DG (1962) Seasonal temperature and precipitation trends at five Minnesota stations. Mon Weath Rev 90: 283-286

Baker DG, Ruschy DL, Skaggs RH (1993) Agriculture and the recent 'benign climate' in Minnesota. Bull Am Meteor Soc $74: 1035-1040$

Baker DG, Watson BF, Skaggs RH (1985) The Minnesota long-term temperature record. Clim Change 7:225-236

Boehm R, (1993) Air temperature fluctuations in Austria 1775-1991: a contribution to greenhouse warming discus-

Editor: V. Meentemeyer, Athens, Georgia, USA sion. Preprint, Eighth Conference on Applied Climatology. American Metorological Society, Boston, MA, J26 - J30

Brinkmann WAR (1983) Variability of temperature in Wisconsin. Mon Weath Rev 111:172-180

Diaz HF, Quayle RG (1980) The climate of the United States since 1895: spatial and temporal changes. Mon Weath Rev 108:249-266

Efron B (1982) The jackknife, the bootstrap, and other resampling plans. JW Arrowsmith, Philadelphia, PA.

Hansen J, Fang I, Lacis A, Rind D, Lebedeff S, Reudy S, Russell $G$ (1988) Global climate changes as forecast by the GISS 3-D model. J geophys Res 93:9341-9364

Hansen J, Lebedeff S (1988) Global surface air temperatures: update through 1987. Geophys Res Lett 15:323-326

IPCC (lntergovernmental Panel on Climate Change) (1990) Climate change: the IPCC scientific assessment. Cambridge University Press, Cambridge

Quinlan FT, Karl TR, Williams CN Jr (1987) United States Historical Climatological Network ( $\mathrm{HCN}$ ) serial temperature and precipitation data. Carbon Dioxide Information Analysis Center, Environmental Sciences Division, Oak Ridge National Laboratory, Oak Ridge, TN

Skaggs RH, Baker DG (1985) Fluctuations in the length of the growing season in Minnesota. Clim Change 7:403-414

Skaggs RH, Baker DG (1986) The contribution of months and seasons to fluctuations of the mean annual temperature in eastern Minnesota. Theor appl Climatol 37:158-165

Skaggs RH, Baker DG (1989) Temperature change in eastern Minnesota. J Climate 2:629-630

van Loon H, Williams J (1978) The association between mean temperature and interannual variability. Mon Weath Rev 106:1012-1017

Ward JH (1963) Hierarchical group to optimize an objective function. J Am Stat Ass 58:236-244

Manuscript first received: June 24, 1995

Revised version accepted: September 5, 1995 